\title{
Interpreting academic integrity transgressions among learning communities
}

\author{
Anuradha Mathrani ${ }^{1 *} \mathbb{D}$, Binglan Han ${ }^{1}$, Sanjay Mathrani ${ }^{1}$, Meena Jha $^{2}$ and Chris Scogings ${ }^{1}$
}

\author{
* Correspondence: a.s.mathrani@ \\ massey.ac.nz \\ 1 Massey University Auckland \\ New Zealand \\ Full list of author information is \\ available at the end of the article
}

\begin{abstract}
Educational institutions rely on academic citizenship behaviors to construct knowledge in a responsible manner. However, they often struggle to contain the unlawful reuse of knowledge (or academic citizenship transgressions) by some learning communities. This study draws upon secondary data from two televised episodes describing contract cheating (or ghostwriting) practices prevalent among international student communities. Against this background, we have investigated emergent teaching and learning structures that have been extended to formal and informal spaces with the use of mediating technologies. Learners' interactions in formal spaces are influenced by ongoing informal social experiences within a shared cultural context to influence learners' agency. Building upon existing theories, we have developed an analytical lens to understand the rationale behind cheating behaviors. Citizenship behaviors are based on individual and collective perceptions of what constitutes as acceptable or unacceptable behavior. That is, learners who are low in motivation and are less engaged with learning may collude; more so, if cheating is not condemned by members belonging to their informal social spaces. Our analytical lens describes institutional, cultural, technological, social and behavioral contexts that influence learner agency.
\end{abstract}

Keywords: Academic citizenship behaviors, Academic integrity transgressions, Cheating, Ghostwriting, Work ethics

\section{Introduction}

Educational institutions are framed inside societies; they exist as intellectual communities whose main purpose is to demonstrate leadership and contribute towards building scholarly and professional knowledge. The institutional fraternity roles go beyond classrooms as they make connections with people and society in the buildup of scholastic activities across various subject disciplines. In doing so, they seek ways to bring in different forms of societal engagements into an academic context in a responsible manner, and vice versa, to advance knowledge forms (Nørgård and Bengtsen 2016). Therefore, academic citizenship integrates personal, professional, societal, technical

(c) The Author(s). 2021 Open Access This article is licensed under a Creative Commons Attribution 4.0 International License, which permits use, sharing, adaptation, distribution and reproduction in any medium or format, as long as you give appropriate credit to the original author(s) and the source, provide a link to the Creative Commons licence, and indicate if changes were made. The images or other third party material in this article are included in the article's Creative Commons licence, unless indicated otherwise in a credit line to the material. If material is not included in the article's Creative Commons licence and your intended use is not permitted by statutory regulation or exceeds the permitted use, you will need to obtain permission directly from the copyright holder. To view a copy of this licence, visit http://creativecommons.org/licenses/by/4.0/. The Creative Commons Public Domain Dedication waiver (http://creativecommons.org/publicdomain/zero/1.0/) applies to the data made available in this article, unless otherwise stated in a credit line to the data. 
and regional fora. An academic citizen's aim is to advance knowledge that has a positive impact on global societies leading to social, scientific, cultural and economic growth across different contexts. The scope of knowledge evolves when new ideas are exchanged across multiple subject disciplines and furthered with online technologies. At the same time, the problem space related to dishonest and unscrupulous practices associated with the unlawful reuse of knowledge instead of its responsible production is also seen to be growing. The perpetrators defense to back their use of dishonest practices is often 'everybody in this was doing it', hence it is not their responsibility alone to be virtuous (Draper and Reid-Hutchings 2019). Therefore, disruptive activities such as those related to third party involvement, for example, the use of paid contractual agreements via online essay mills/factories and file-sharing platforms are taking shape (Bretag et al. 2019). Contract cheating or what is commonly referred to as ghostwriting is unlike traditional plagiarism; it is designed to defeat text matching software wherein paid contractors produce original content, so that authorship can be validated as student-produced work (Amigud and Dawson 2019). Unfortunately, institutions have limited abilities to invalidate student authorship if the ghostwritten content is not discovered by any text-matching software as unlawfully gained content. Moreover, these contract cheating sites openly operate their online essay mills/factories and are difficult to prosecute since litigation laws are non-uniform across national boundaries (Draper and Newton 2017).

Educational institutions rely on e-learning tools for their teaching and learning enterprise needs. Online models offer a comprehensive, cohesive and integrated set of elearning tools that can connect dispersed learners with institutional resources in a very cost-effective way (Mays et al. 2018). The mediating e-learning tools provide virtual and transportable learning spaces that are location unaware. Classrooms have moved beyond physical rooms to online forums and a layer of abstraction has penetrated into existing teaching and learning environments. That is, learners' environments are split into local (or physical) space and global (or online) space. In the face of this physical disconnect, educators need assurance that learners are not capitalizing on rewards that do not rightfully belong to them, such as from the use of online purchased content. Development of knowledge is both a responsibility and a service; therefore, correct means used for producing this knowledge is paramount. Unfortunately, the interplay between societies and education in creating knowledge can be experienced in two opposite directions. It can be viewed as a submission versus an empowerment, as a dismissal versus an invitation, or as a disruption versus an engagement (Gieryn 2000). Positive emotions like empowerment, invitation and engagement enhance citizenship behaviors to provide a target-based focused view (Chiaburu et al. 2018), while emotions relating to submission, dismissal or a disruption endorse less meaningful views that showcase a lack of self-control (Rundle et al. 2019) leading to academic integrity transgressions. A disengaged approach causes disturbances in learning and leads to a spectrum of deliberate negative behaviors, where learning is often considered a trade that can be acquired by transactional or contractual means (Bretag et al. 2019). Such behaviors that exhibit lack of academic integrity have recently been reported in many public media postings.

In this article, we develop an analytical lens to understand contexts around negative academic citizenship from a learner's perspective. Specifically, international 
communities are examined since our inquiry utilized secondary data from two recently televised news items that focus on ghostwriting practices common among international student groups (TVNZ-Report 2019a, 2019b). We acknowledge that television reporting is different from academic reporting, as episodes are telecasted with more eyecatching content to heighten viewers' interest. However, our purpose is to better understand some aspects of academic citizenship transgressions from these televised reports, with the analytical lens that has been derived from academic theories.

On the background of already existing theories namely Five Factor model (FFM) (McCrae and Costa 2005) and socio-cultural ecology (Pachler et al. 2010), we aim to provide a theoretical base to inform institutions on the underlying rationale behind cheating behaviors. Current teaching and learning environments are aided by online media tools that offer ease in administration, management and the overall delivery of educational courses. Structures in the coursework are enforced by intertwining pedagogical interventions with online tools and have led to learning environments that are spread across both formal and informal spaces. Ongoing learning interactions across formal spaces (e.g., classrooms, institutional course portals, etc.) and informal (e.g., online social groups, student community rooms, etc.) provide a context for cultural practices to take shape. Learners negotiate and internalize their professional practice which affects their agency, that is, their conscientious use of learning resources as they strive to maximize their learning outcomes (Pachler et al. 2010). Whether the outcomes achieved by learners have been earned lawfully or by deceitful means is a big question that is currently faced by educational institutions.

In our study, we have examined learner agency within the learning structures and cultural settings that existed in the televised broadcasted context. Our analytical lens rationalizes and deconstructs student concerns and the impact on their agency (or, their lack of agency, such as the submission of ghostwritten essays for assessment purposes). It explains how the learning process is informed by learners' attitudes towards achieving their learning outcomes, which are in turn influenced by their motivational and self-confidence levels, emotional stability and their overall intellectual curiosity (Berry et al. 2007; Gore et al. 2012). Our study thereby contributes to the framing of an analytical lens for examining the influence of different contexts such as technological, cultural, social and behavioral contexts for interpreting academic integrity transgressions among the learning communities.

\section{Academic integrity transgressions}

Bretag et al. (2019) identify a transactional spectrum of academic integrity transgressions ranging from sharing behaviors to cheating behaviors. Sharing behaviors lie at the lower end of the transactional spectrum and comprise buying/selling notes or sharing completed assignments (which could be for any reason like referring or copying). Sharing behaviors could subsequently lead to cheating behaviors, where the transactions become more deceptive. Behaviors can range from obtaining a completed assignment via ghostwriting agencies, to providing or receiving exam assistance or to impersonating someone else at the exam venue. The availability of peer-to-peer networking sites and online tools (e.g., ThinkSwap (www.thinkswap.com), Course Hero (www.coursehero. com), Baidu Library (www.wenbku.baidu.com), GoParaphrase (www.goparaphrase.com) 
or Paraphrasing Online (www.paraphrasingonline.com)) have added to more types of technology-driven misdemeanors and cheating instances (Bretag et al. 2019).

Educational institutions are working towards containing learner misdemeanors. Some studies have highlighted cheating behaviors to be particularly rampant among some student communities, such as international students or in English language schools (Bertram et al. 2015). Having said this, we cannot ignore that international students add to the host country's social, cultural and economic growth (Christian and Mathrani 2014). With the limited funding instruments currently being sanctioned by governments, universities seek ways to increase their international student intake. International students are charged much higher fees compared to domestic students (Sá and Sabzalieva 2018). Currently, international education is the 4th largest export industry worldwide (Bagshaw 2018; Group Of Eight 2014). At the same time, international students are particularly vulnerable, as they face a different social, cultural and linguistic environment from their home country. Moreover, the high cost of living in a foreign country combined with excessive fee structure can add to an international student's sense of desperation and anxiety, especially if they are unable to engage with the subject content. Sometimes the reasons for learner misdemeanors could also stem from a feeling of entitlement, or from a simple lack of discipline (TVNZ-Report 2019b). Therefore, ensuring that academic integrity and civic values are maintained is very much an ongoing problem for educational institutions globally.

\section{Theories on learning and human behaviors}

Scholastic activities are meaningful if the institutional stakeholders "have a sense of (co) ownership and feel agency" in relation to their academic practice (Nørgård and Bengtsen 2016, p.8). Agency manifests from learners' perceptions of their learning environment and is enhanced when the learners view the environment as a potential resource for learning and where the learner can make meaningful contributions (Pachler et al. 2010). In this study, we take this aspect of agency to understand academic integrity behaviors. An individual's behavioral spectrum can range across different work ethics levels. McCrae and Costa (2005) have defined the five-factor model (FFM) to lay out personality traits that influence positive (i.e., citizenship) and negative (i.e., unethical) workplace behaviors. The five traits, namely extraversion, agreeableness, conscientiousness, neuroticism and openness to experience have been used to understand organizational (Helle et al. 2018) and academic (Gore et al. 2012) citizenship. High extraversion implies socially interactive behaviors, while low extraversion relates to reserved and independent people. Highly agreeable individuals are trusting and caring, while less agreeable people are more self-centered. Conscientiousness indicates a person's work ethics to be high or low. Highly conscientious people are plan driven as they strive to achieve their tasks, while people low in conscientiousness are irresponsible and try to avoid hard work (Barrick et al. 2001). Neuroticism relates to emotional stability when a person is faced with new circumstances, and, openness to experiences characterizes enthusiasm as learners adapt themselves in new situations (McCrae and Costa 2005). The FFM taxonomy has been applied extensively in understanding workplace behaviors and for other personality issues (e.g., (Chiaburu et al. 2018; Widiger and Costa Jr. 2013)). 
Using Pachler et al.'s (2010) socio-cultural ecology and McCrae and Costa's (2005) study, we have set out to frame an analytical lens for understanding academic integrity transgressions. Pachler et al.'s work conveys how formal and informal learning ecosystems have evolved with appropriation of online technologies. They have laid emphasis on appropriation of handheld learning devices (referred as mobile complex) because of their mobility, portability, multi-functionality, interactive ability, connectivity and ubiquity, all of which engages learners and brings them a sense of ownership and belongingness. However, in this study we consider all web-enabled devices as part of the mobile complex. Research on the use of technology or mobile complex as a curricula medium is evolving (Pachler et al. 2010; Sharples et al. 2006). Handheld devices (e.g., smartphones, tablets) have the potential to shift the onus of learning to the learner. Pachler et al. have proposed a socio-cultural eco-system comprising three components, namely structures, cultural practices and agency. The institution is viewed as a space where emergent teaching and learning structures are informed by cultural practices. Institutional cultural practices are extended by a learner's personal learning space; this enables the learner in making meaningful use of available structures to achieve their learning outcomes. Learning spaces are entangled in structures that are imposed by the way technology is used in formal and informal teaching and learning environments. How learners take command of their learning over entangled structures and within an institutional and a personal cultural space, is reflected in their agency. Meaningful use of technology enhances the agency of learners and builds their skillsets and competencies. As new learning experiences are gathered, they further influence citizenship behaviors, which may either enhance agency or may undermine overarching academic values and ideologies.

The FFM personality traits - extraversion, agreeableness, conscientiousness, neuroticism and openness to experience - have been studied for understanding of organizational citizenship behaviors (Berry et al. 2007). Gore et al. (2012) extended this to academic citizenship behaviors and they associated conscientiousness most with academic citizenship. High conscientiousness indicates strong work ethics with a tendency towards persistence and hard work. They explained from a civic virtue perspective that an agreeable person is a trusting and collaborative team player, who can tolerate indiscretions from their team members. Next, neuroticism indicates emotional stability and the person's ability to handle work pressures. People high in neuroticism are more anxious and diffident. They cannot easily adjust to new situations as they have a tendency to focus more on themselves rather than actively participate with their external environments. Finally, people high in openness to experience are creative as they reflect on ways to utilize their know-how to the task on hand. These individuals are less likely to complain when faced with new learning experiences. However, Gore et al. add that personality traits indicate a propensity towards the citizenship behavior that is adopted in given scenarios and does not directly reflect on their civic virtues. Indeed, workplace behaviors are discretionary that cannot be explicitly extracted from traits, rather they inform our personal choices, thereby defining the nature of citizenship behavior that will be adopted (Podsakoff et al. 2000). Traits lead to various emotions that may have conflicting connotations in different workplace scenarios, and therefore need careful consideration. This study is related to academic citizenship domain from a learner's perspective that is based upon formal reward systems (i.e., achievement of grades) and 
workplace compliance (i.e., assessment completion) in different cultural settings (i.e., foreign university). Prior research has found a link between academic honesty with future ethical workplace behaviors; however, these studies face many methodological challenges such as the use of cross-sectional data from self-reported survey measures rather than the use of longitudinal data, or from some business ethics simulation scenario (Bratton and Strittmatter 2013; Gore et al. 2012). Therefore, the quest for understanding motivating factors that enrich academic citizenship behaviors is still ongoing.

\section{Framing of the analytical Lens}

The socio-cultural ecology model by Pachler et al. (2010) and the FFM model underpin the framing of the analytical lens for understanding learner transgressions. Mediating technologies have extended learners access to cover more learning resources and have augmented learning spaces to include both formal and informal spaces. This has brought about much change in socio-cultural structures that earlier governed classroom settings. Learning has become more individualized and therefore has allowed construction of more forms of personal agendas. This has both positives and negatives. That is, while it can give a personalized learning experience and foster collaboration and communication, it can also lead to distraction where learners may collude and indulge in ghostwriting tactics. Pachler et al. defines coursework as a frame-based structure that encompasses pedagogical interventions such as lessons, discussions, assessments, exams, etc. Gieryn (2000) states that life forms are emplaced, that is, social and cultural entities are grounded in geographical locations that imposes structure and informs how new experiences, interpretations and imaginations are shaped. In the context of this study, instructors and students are situated in teaching and learning spaces where they engage in various scholarly activities to contribute to their academic discipline. However, mediating technologies have blurred the physicality of these spaces to bring in virtuality, which in turn could lead to environments that either promote academic citizenship or endorse dishonest behaviors.

Cultural experiences take shape in the blending of mediating technologies with the institutional teaching and learning practices. Pachler et al. consider learning to be a ubiquitous social feature that allows for representational affordances. Learning experiences are captured via media such as YouTube videos, pictorial exhibits or classroom recordings, or over online discussion forums and in digitized files (e.g., pdf). The reproducibility of these representations have opened up a different perspective. Learning experiences are no longer limited to hand-written notes and classroom discussions. Rather, learning has shifted to informal online spaces that offer a different sociocultural space, and where learners can configure the technology individually to suit their own needs. Configurations can promote academic citizenship where learners utilize online resources conscientiously to collaborate and share their learning experiences. For instance, users can actively engage in 'shaping their own forms of individualized generation of contexts for learning' to produce homework that is 'interlaced with humor' (p. 23). Alternatively, negative configurations can lead to dishonest behaviors (termed as sharing and cheating behaviors by Bretag et al. (2019)) that compromise on work ethics where learners collude and falsely claim someone else's work as their own. Pachler et al. add that how learners' appropriate technologies for setting up their learning contexts depends upon their social adaptation and in the adoption of agency. 
Agency encourages active participation in the production of these artefacts and demonstrates hard work, collaboration and willingness to be challenged. On the other hand, mere consumption of media artefacts could include collusion, plagiarism or use of contract essay writing agencies (Newton 2016). Therefore, manifestations of citizenship behaviors are based on individual and collective perceptions of what constitutes as acceptable or unacceptable behavior.

Figure 1 illustrates the analytical lens that has been framed from three components (structure, cultural practices and agency) of Pachler et al.'s (2010) socio-cultural ecology model, and the four personality traits (conscientiousness, agreeableness, neuroticism and openness to experience) identified by Gore et al. (2012) for academic citizenship from the five factor model. Academic citizenship behaviors are informed by combination of personality traits across the three components. That is, collaborative or disruptive behaviors result from "interdependent, entangled social and technological structures, the users' agency and cultural practices" (Pachler et al. p. 18). The four personality traits (shown in the intersection of the three entangled components in Fig. 1) influence a learner's propensity to behave in a certain manner. Their behavior can be spread across a broad range of personality traits. Learners that exhibit persistence and hard work have high conscientiousness. They demonstrate intellectual curiosity due to high openness to experience, are outgoing or very agreeable, and display selfconfidence or low neuroticism, as they seek rewards based on their personal achievements. The other end of the spectrum are learners with low conscientiousness, less openness to new experiences, high neuroticism and less outgoing behaviors.

\section{Methodology}

The research study has utilized secondary data, that is from two exclusive television episodes that were telecasted on 15th and 22nd May 2019 (TVNZ-Report 2019a, 2019b). These televised episodes reported ghostwriting strategies with improper use of paid

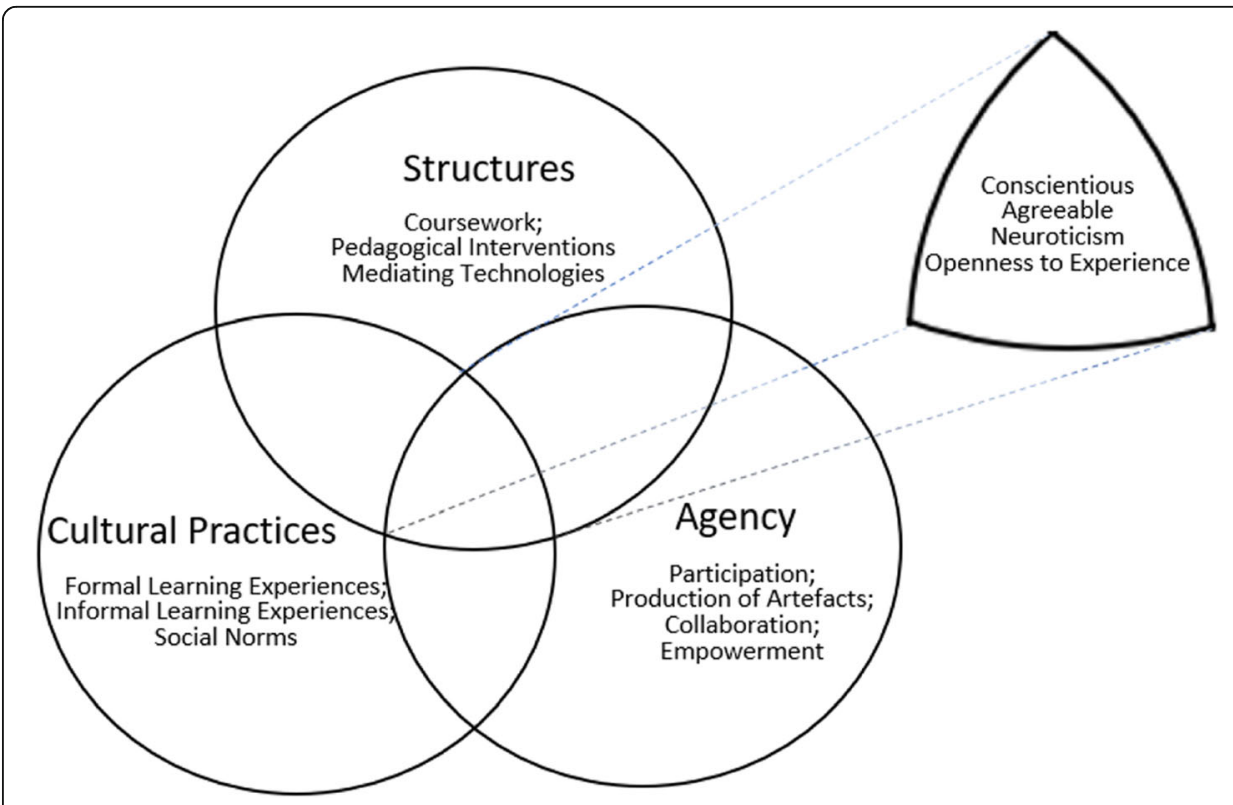

Fig. 1 Analytical Lens for Academic Citizenship Behaviors 
contract writing agencies by university students. Secondary research allows for greater interaction between theory and empirical data because the researcher is not burdened with the practicalities of data collection (Hakim 1982); although their data analysis is limited by lack of opportunity for follow-up to gather additional data or specifics of the data collection processes (Johnston 2012, 2014). Moreover, secondary data such as commercial output from investigative journalism comprises "action news" that are more inclusive of sensitive findings than scholarly output (Haggerty 2004). For example, an investigation on 'ghostwriting' by instructors working in tertiary institutions would be deemed sensitive since it poses risk of harm and discomfort to students if their identities are made known to the instructors. This is even more so with the power differential that exists between the student and their instructor. The instructor's personal judgmental stance could compromise the validity of the reporting (Bush 2007). Students too would not be willing to openly express their engagement with contractual ghostwriting agencies to university affiliated researchers. Haggerty adds that university affiliated researchers are constrained in how knowledge is produced on pressing social issues since their work is subjected to intense ethical scrutiny. Academics must outline the specifics of any potential harm that their research might produce and the procedures to alleviate these harms before commencing their research; however, with secondary data, they are excluded from such forms of ethical vetting. Therefore, televised reporting provided us an opportunity to understand transgressional behavior without causing discomfort or harm to student groups. The use of televised media stories enabled confidentiality of student identities and offered us with an insider view in our exploration of behavioral traits that could lead to academic transgressions.

The analytical lens (shown in Fig. 1) informed our investigation. Pachler et al.'s (2010) socio-cultural ecology model and the four personality traits identified by Gore et al. (2012) provided a baseline for identifying relevant themes. Investigator triangulation helped in manually coding of themes. Each member of the author team viewed the TV recording and read the transcribed text many times. We used a document collaboration platform (Google Docs) that allowed each co-author to work on the same document to extract relevant themes. The proviso being that the extracted themes showcased context-driven judgement and provided a clear audit trail that allows readers to understand how these themes have been synthesized (Levitt 2015; Twining et al. 2017). Therefore, investigator triangulation (i.e., having five investigators involved in the data analysis) led to substantive analysis which has helped in building credibility and trustworthiness in our evaluation (Lincoln and Guba 1986). Moreover, since the data used in this study was made available over public platforms (via television and newspapers), hence permission for the use of secondary data was not required. Care has been taken in our reporting of selected verbatim snippets to maintain anonymity of the participants and institutions. The reported snippets have been integrated with an interpretive commentary to provide a broader social context for framing our discussions.

\section{Secondary data: summary of the televised episodes}

This section briefly summarizes two exclusive television episodes which were also later made available on the official website of the television channel (TVNZ-Report 2019a, 2019b). The episode titles were "Buying essays from ghostwriters allegedly widespread among international students at NZ universities" and "NZ lecturer says half of international students in their class failed for cheating, universities turning blind eye". As 
these titles suggest, the televised reports covered widespread nature of academic integrity transgressions via ghostwriting strategies where international student communities used contract writing agencies for writing up their course assignments. It mentioned a 2014 civil case where a contract agency was investigated under the Proceed of Crime Act for writing over 11,500 essays over a seven-year period. This contract agency had profited over $\$ 4.6$ million from ghostwriting practices, of which only 2 million was recovered by the police. It further alleged that ghostwriting was a commonly used practice among international students, which has become worse over the years.

In the report, one staff member (whose identity and institution has been kept anonymous) had stated: "Higher education has become a simple commercial transaction. Pay the money, pass the paper". Further, students who were interviewed also admitted to having used third party agencies like Taobao (i.e., the Chinese equivalent of Amazon) to purchase essays which they submitted as their assignments.

In one televised item, the reporter pretended to be an international student where he contacted a third party that is well known for writing essays. Text conversation messages between the reporter and the third party have revealed the extent of transactional approach towards learning. Each word of the ghostwritten text has an associated transactional cost, as is evident from the snippet below.

Basically we charge 20 New Zealand cents a word. An urgent or a guaranteed A grade essay costs more. Just send me your essay topic, then I can arrange a writer for you. We just helped a girl studying pre-school education in New Zealand to write her assignment.

Further, the report adds that overseas students are prized income for the cash-strapped New Zealand's tertiary institutions and "the money is so important to universities". The government is launching global campaigns to attract more international students as overseas students can contribute much to the country's economic growth. They estimated a contribution of $\$ 4.6$ billion dollars each year to the country's economy. The report calls the learning pathway as 'murky' and recommends that educational institutions "get to the bottom of cheating allegations". It suggests a "sector-wide review", although their suggestion has been "played down" and "rubbish [ed]" by educational institutions that are operating in the region.

Another report by Group of Eight Universities in Australia (2014) identified international students as generators of economic strength and wealth. They state that each student contributes an average of $\$ 51,000$ in non-fee income through rent, food, house supplies, utilities, transport costs, medical and health costs. They further recommend that "the work rights of international students be extended to two years upon graduation" to address the country's skill shortage (p. 5). Therefore, commercialization of education provides significant spillover benefits that contribute to the country's economic footprint for its long-term prosperity.

\section{Discussion}

This section provides a dialogue on the analytical lens using the above television report data. We identify themes related to structure, cultural practices and agency. To better describe the behavioral traits that lead to academic integrity transgressions across these 
three themes, we have provided a data-based narrative by using first person quotes. By not smoothening the narrative to a third person, we aim to convey both the depth and richness of the exchanged messages to provide a more compelling story (Spencer et al. 2003).

Structure relates to coursework comprising taught material and the assessment methods. Many of the assessments have much scope for impersonation as they are delivered in a typed format which can be easily purchased from third party agencies (e.g., Taobao) and used as is. While copying verbatim or other forms of plagiarism can be detected by online tools (e.g., Turnitin, Plagiarisma, Copyscape), a newly composed essay that is ghostwritten by a contractual agency instead of the student cannot. These agencies freely advertise ghostwriting services in country-specific websites, which are easy to find by students that come from those regions. Different grade essays are priced differently ["An urgent or a guaranteed A grade essay costs more"]. Enrolled students are members of international student association groups who inform each other of various ghostwriting services or offer such services themselves ["people come to student activities and sidle up to first years offering their essays for cash services"].

International students soon become aware of ghostwriting services ["I paid someone else to write essays for me during the start of uni"]. Once assured of the quality of ghostwriting services, these students actively used these services ["I've done it about five to six times"] and recommend them to other members who belong to the same cultural group. Soon, it becomes common practice ["There's a large number of international students buying their essays. They definitely know they're cheating"]. Ghostwriting is no longer a taboo topic and acceptance of cheating takes shape. It could lead to some form of pride in having got away with it. When one student was asked "Do you consider yourself a cheat?", the student responded with a "Yes" without hesitation.

Ongoing participation among closely knit similar cultural groups adds to the widespread use of third- party services for ghostwriting. Confidence in continuing the cheating activity grows within the small fraternity as there is seldom any fear of negative consequences to their cheating ["But I haven't heard of anyone I know who's been punished for buying essays"]. Together, these groups collude and empower each other to continue with the unscrupulous activities. One student commented "half the international students ... are buying other people's work and passing it off as their own". While this measure of "half" is one student's estimation which cannot be a measure of the actual cheating prevalence rate, it reinforces that some students are willing to become consumers of other people's work which they do not hesitate to pass off as their own. Some literature suggests contract cheating to be a growing trend indicating that $15 \%$ of current students will pay someone else for contract cheating by the end of the course (Lancaster 2020; Newton 2018).

People high in conscientiousness take pride in their personal performance and exhibit a strong work ethic (Barrick et al. 2001). But this report shows that pride in personal performance could be related to increased number of cheating practices, with one student mentioning that they had used ghostwriting services five to six times. Students also rationalize that since cheating is prevalent among their peers, it is acceptable practice and therefore should not be condemned as misconduct (Rundle et al. 2019). High neuroticism is a result of anxiety and hostility where the focus is on themselves in comparison to the outside environment. While there was no direct display of neurotic 
behaviors in this report, there was much mention of collusion amongst members of similar cultural groups. Being aware of each other's cultural anxiety (such as their poor English writing skills) and financial anxiety (resulting from high fee structure and high living expenses), they are quick to advise newcomers about the availability of ghostwriting services. Locke et al. (2017) refers to such beliefs as injunctive norms or the belief that availing of ghostwriting services constitutes acceptable behavior in the given situation. Tensions over course assessments (such as writing essays) are not channelized constructively to encourage agency among learners, rather it is channeled in compromising of academic values and ethical standards. Finally, learners high in openness to experience are creative, reflective and seek intellectually challenging tasks to maximize their learning. Consumers of ghostwriting services were disengaged with their coursework. Their vision was limited to achievement of a "degree with international clout" for which they have been charged a higher fee compared to the domestic student fee. Therefore, there is some expectation that they are awarded a degree in lieu of international fee payment, even if it involves the use of dishonest tactics.

Besides, having to pay higher fees, international students have to manage their living conditions away from their home country. With limited living allowances leftover after payment of international fees, a level of anxiety or a heightened sense of neuroticism is developed. These students feel less anxious in communities where the community members are from similar cultural backgrounds. Cheating is not considered to be a dishonest or a taboo topic within closely knit communities. Importantly, these communities could comprise both local and international student members. In social structures that are considered safe, the community members share personal ghostwriting experiences, especially in those cases where their cheating was undetected and good grades were awarded. Or, members may support each other by sharing their previous academic year's assignments. The collusion amongst members from closed communities can have a transactional side that involves payments for cheating services that are offered. The fear of cheating consequences is minimal, as they see other students get away with cheating practices. Added to this attitude is low conscientiousness levels that consider learning in terms of a submission rather than an intellectual stimulation. Further, access to contractual cheating arrangements lowers their enthusiasm in meaningfully engaging with the coursework. Rather than trying to achieve their learning outcomes using honest means, the students often fall back on other forms of assignments production.

Figure 2 summarizes these findings using the analytical lens derived from Pachler et al.'s (2010) and Gore et al.'s (2012) research. The analytical lens reveals ghostwriting practices as an outcome of attitudes framed by personality traits, namely, conscientiousness, neuroticism and openness to experience within an educational context. We did not see any characterization of the agreeableness trait in our limited sample. Our analytical lens shows relevant learning structures come from coursework demands, didactic teaching and learning practices, and from technology affordances and constraints. Cultural practices are shaped by collective identity and acceptable social norms. In this case, it relates to everyday experiences such as how other members in the community have overcome their learning challenges. Agency is reflected in how learners utilize their competencies to responsibly achieve their learning outcomes.

The position of the three personality traits are interchangeable across the three components of Pachler et al.'s model in Fig. 2. This is because academic practices are 


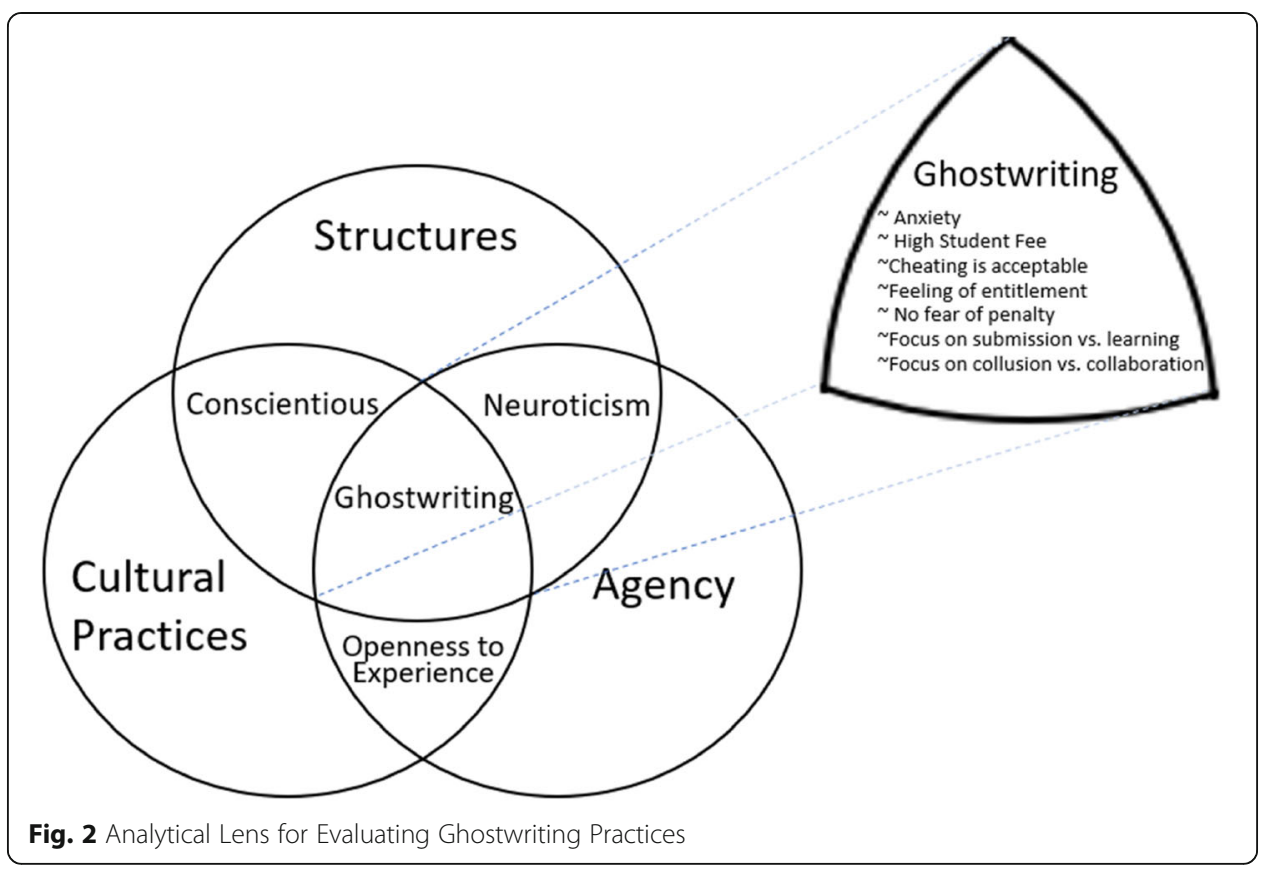

evolving and shaping the habitus of learning. The learners' world is influenced by learning opportunities (or cheating opportunities in this case) from ongoing formal and informal social experiences that take account of the existing structural and cultural norms (Jawitz 2009). Consequently, cheating behaviors can result from any combination of the three traits across the three components to reflect the mental conditioning of the learner in their pursuit to maximize rewards.

We would like to reiterate that secondary data from televised content (TVNZ-Report 2019a, 2019b) has been used in this study. The purpose of the data generated was not for academic reasons, rather for public viewing. We acknowledge that television programs are provocative; but in being so, they bring out those difficult questions that would otherwise be difficult to raise. Moreover, journalistic inquiry aided in providing an alternative perspective and establishing a link between the secondary data description of the social, cultural and institutional context with our proposed theoretical model (Smith 2008). In this sense secondary data provided us an insider view of the otherwise guarded tactics that may be employed by some student communities.

\section{Conclusion}

This study has provided a new interpretation of why academic integrity transgressions occur among learner communities. We call upon the interplay between learner communities and their use of technology in a diminished context. Prior studies have built upon the use of technological devices as an ecosystem that reinforces interplay between learning, entertainment and engagement (Pachler et al. 2010); however, we have differentiated this ecosystem with that of submission (versus learning), anxiety (versus entertainment) and disengagement (versus engagement). An anxious and disengaged approach leads to learning disruptions that have been witnessed as academic transgressions in higher education (Bretag et al. 2019). Using three personality traits, namely, conscientiousness, neuroticism and openness to experience, from the five traits (i.e., extraversion, agreeableness, conscientiousness, neuroticism and 
openness to experience), we have provided some evidence of personality traits that could influence academic integrity transgressions. Low academic conscientiousness indicates low tendency towards hard work in achieving learning outcomes. High neuroticism refers to high degree of anxiety in new situations and where the person has to exert their mental abilities, such as writing essays in a foreign language (English) for completing assessment tasks. Finally, people low in openness to experience are less engaged in learning activities that are more challenging and require more creativity. Therefore, academic citizenship requires high academic conscientiousness, low neuroticism and high openness to experience perspectives to shape agency.

Taken together, the socio-cultural ecology model combined with three personality traits (that are a subset of the personality traits of the five-factor model) has provided an analytical framework to improve our understanding of academic citizenship behaviors. Our analysis was based on televised reports; therefore, no primary data was used. However, the study has provided rich insights on the relationship between structures (imposed by coursework, assessments, etc.), cultural practices of socially connected student groups (i.e., international students who face similar language barriers), and agency or lack of agency. A lack of agency promotes collusion among community group members rather than collaboration. Learners are likely to compromise on their work ethics and adopt a lazy and dishonest approach if they see other members of their communities do the same. Educational institutions should adopt a holistic culture of academic integrity rather than think of academic integrity as an individual responsibility (Bretag et al. 2014). We suggest that institutions consider providing cultural and pastoral support to strengthen attitudes and academic citizenship behaviors. This involves making students understand what constitutes academic integrity breaches and how they should be accountable in their role as academic citizens.

Moreover, our study reveals that essay writing assessments could be a cause of concern for international students. The learning process of writing essays needs more careful design in laying out personal thoughts, theoretical frames and analytical works which require an academic 'voice' (Wendt and Åse 2015). Telling an international student to download a lengthy document on essay writing is by no means supportive (Bretag 2007). Essay writing poses challenges for the learners who have English as their second language. The passing score band of 6.0 to 6.5 for second language learners from the International English Language Testing System (IELTS) is very low in comparison to an educated native speaker that generally fall between the 8.5 to 9 band (Bretag 2007). While this one score enables international students to meet admission entry requirements, they often face difficulties coping with higher degree study in English, including comprehension of course material or in understanding assignment requirements (Johnson 2008). Johnson's study revealed that international students from one New Zealand university considered their first year of study to be "terrible" where "they had understood between 20 and 30 percent of the lecture content" (p.235). International students further face difficulty in understanding local accents and are scared to converse with members from diverse cultural groups for fear of being stereotyped (Christian and Mathrani 2014). Poor linguistic abilities can heighten neuroticism and isolate the learner from openly engaging in conversations with instructors and expressing their learning challenges. Therefore, more pedagogical strategies may need to be thought of and designed for promoting openness and ensuring a more even assessment platform. 
Bretag (2014) says education institutions depict a "layout for human experience" (p. 7). If institutional structures are not supportive, it could lead to lack of agency among students and the academic staff which could erode education standards. While institutions have increased their earning as a consequence of large number of international student enrolments, their investments have been focused mainly in increasing administration staff numbers and for marketing purposes (so as to generate even more revenue) rather than on increasing academic staff numbers (Unconventional Economist 2019). The high student-to-academic staff ratios places more pressure on teaching staff for maintaining education quality standards. Therefore, academic citizenship also hinges on how much institutions value their teaching staff. Academic citizenship must be channeled top-down (institution to academic staff to learner) and also bottom-up (learner to academic staff to institution). Institutions, academic staff and students all have a role to play in upholding academic integrity. A recent survey report has revealed that academic staff are often pressured directly by their management to pass higher proportions of students, or, they are indirectly warned that a lower pass rate may result in their course offering being withdrawn (Kenny 2019). Institutional structures must support their academic staff in maintaining quality of education standards and provide them with avenues that promote a safe working environment. With the commercialization of education, it is essential that institutions frame teaching and learning structures with the intent to support their academic staff and the diverse learner groups in enhancing their agency. "Detecting cheating cases and improving academic integrity are complementary, not contradictory" (Dawson and Sutherland-Smith 2019, p. 716); therefore, academic citizenship is an outcome of quality and integrity of the overall education system and is everyone's responsibility.

A newly drafted legislation Tertiary Education Quality and Standards Agency Amendment (Prohibiting Academic Cheating Services) Bill 2019 by the Group of Eight Universities in Australia has implications for academic misconduct, be it in the form of plagiarism, ghostwriting or cheating in examinations (Thomson 2019). It has additional clause for sanctions to be imposed as per the university rules if fee-for-cheating service is detected. However, the sanctions are not explicitly stated, such that it warrants a civic penalty or is considered an offence. Further robust mechanisms (under section 114B) to prohibit advertising cheating services are being drawn. Finally, to uphold the academic reputation of the higher education sector, institutions are being encouraged to inform higher education regulators of commercial cheating services that they may encounter.

In conclusion, upholding of academic citizenship values has a much broader societal context that includes both institutional and individual agency. It depends upon the ways institutional structures are being negotiated by the authorities, learner communities and individuals to support professional practices in employing agency to achieve positive learning outcomes and develop a sense of personal responsibility. Although informed by televised reporting, our analytical lens has described how institutional, cultural, technological, social and behavioral contexts influence learners' participation and their attitudes towards learning to help us better understand academic integrity transgressions. 
Authors' contributions

1. Anuradha Mathrani =30\%. 2. Binglan Han =20\%. 3. Sanjay Mathrani =20\%. 4. Meena Jha =15\%. 5. Chris Scogings $=$ $15 \%$. The author(s) read and approved the final manuscript.

\section{Funding}

Not applicable. No external funding was used.

\section{Availability of data and materials}

The study has used secondary data which is publicly available.

1. TVNZ Report (2019a, 15th May, 2019). One News [Television series episode], Buying essays from ghostwriters allegedly widespread among international students at NZ universities. Auckland, New Zealan (https://www.tvnz.co.nz/one-news/newzealand/exclusive-buying-essays-ghostwriters-allegedly-widespread-among-international-students-nz-universities).

2. TVNZ Report (2019b, 22nd May 2019). One News [Television series episode], NZ lecturer says half of international students in their class failed for cheating, universities turning blind eye. Auckland, New Zealand. (https://www.tvnz.co.nz/ one-news/new-zealand/nz-lecturer-says-half-international-students-in-their-class-failed-cheating-universities-turningblind-eye).

\section{Competing interests}

The authors declare that they have no competing interests.

\section{Author details}

Massey University Auckland New Zealand . ${ }^{2}$ Central Queensland University Sydney Australia .

Received: 11 September 2020 Accepted: 31 January 2021

Published online: 04 March 2021

\section{References}

Amigud A, Dawson P (2019) The law and the outlaw: is legal prohibition a viable solution to the contract cheating problem? Assess Eval High Educ 45(1):98-108. https://doi.org/10.1080/02602938.2019.1612851

Bagshaw E (2018, 14 august 2018) in the media: universities report says students add $\$ 1.5$ billion to Treasury revenue. Sydney morning herald. https://www.smh.com.au/politics/federal/universities-report-says-students-add-1-5-billion-to-treasuryrevenue-20180813-p4zx6s.html. Accessed 14 Sept 2018

Barrick MR, Mount MK, Judge TA (2001) Personality and performance at the beginning of the new millennium: what do we know and where do we go next? Int J Sel Assess 9(1-2):9-30. https://doi.org/10.1111/1468-2389.00160

Berry CM, Ones DS, Sackett PR (2007) Interpersonal deviance, organizational deviance, and their common correlates: a review and meta-analysis. J Appl Psychol 92(2):410-424. https://doi.org/10.1037/0021-9010.92.2.410

Bratton V, Strittmatter C (2013) To cheat or not to cheat?: the role of personality in academic and business ethics. Ethics Behav 23(6):427-444. https://doi.org/10.1080/10508422.2013.811077

Bretag T (2007) The emperor's new clothes: yes, there is a link between English language competence and academic standards. People and Place 15(1):1-13. https://search.informit.org/doi/10.3316/informit.334865480475401

Bretag T, Harper R, Burton M, Ellis C, Newton P, Rozenberg P, Saddiqui S, van Haeringen K (2019) Contract cheating: a survey of Australian university students. Stud High Educ 44(11):1837-1856. https://doi.org/10.1080/03075079.2018.1462788

Bretag T, Mahmud S, Wallace M, Walker R, McGowan U, East J, Green M, Patridge L, James C (2014) Teach us how to do it properly!' An Australian academic integrity student survey. Stud High Educ 39(7):1150-1169. https:/doi.org/10.1080/03075079.2013.777406

Bush T (2007) Authenticity in research - reliability, validity and triangulation. In: Briggs A, Coleman M (eds) Research methods in educational leadership and management, 2nd edn. Sage, London, pp 91-105

Chiaburu DS, Oh IS, Marinova SV (2018) Five-factor model of personality traits and organizational citizenship behavior. In: Podsakoff P, MacKenzie S, Podsakoff NP (eds) The Oxford handbook of organizational citizenship behavior. Oxford University Press, New York, pp 203-220

Christian S, Mathrani A (2014) ICT Education: Socio-Learning Issues Faced by International Students. In: Myers M, Straub DW (eds) Proceedings of the Thirty Fifth International Conference on Information Systems, ISBN 978-0-615-15788-7. 14-17 December 2014. Auckland, New Zealand

Dawson P, Sutherland-Smith W (2019) Can training improve marker accuracy at detecting contract cheating? A multidisciplinary pre-post study. Assess Eval High Educ 44(5):715-725. https://doi.org/10.1080/02602938.2018.1531109

Draper MJ, NewtonPM (2017) A legal approach to tackling contract cheating? International Journal for Educational Integrity. 13:11 ISSN: 1833-2595. https://doi.org/10.1007/s40979-017-0022-5

Draper MJ, Reid-Hutchings C (2019) Are essay mills committing fraud? A further analysis of their behaviors vs the 2006 fraud act (UK). International journal for educational Integrity.15:11 ISSN: 1833-2595. https://doi.org/10.1007/s40979-019-0050-4

Gallant BT, Binkin N, Donohue M (2015) Students at risk for being reported for cheating. Journal of Academic Ethics 13(3): 217-228. https://doi.org/10.1007/s10805-015-9235-5

Gieryn TF (2000) A space for place in sociology. Annu Rev Sociol 26(1):463-496. https://doi.org/10.1146/annurev.soc.26.1.463

Gore JS, Kiefner AE, Combs KM (2012) Personality traits that predict academic citizenship behavior. J Appl Soc Psychol 42(10): 2433-2456. https://doi.org/10.1111/j.1559-1816.2012.00948.x

Group Of Eight (2014) Policy Note: International students in higher education and their role in the Australian economy. https:/go8.edu.au/ files/docs/publications/international_students_in_higher_education_and_their_role_in_the_australian_economy.pdf. Accessed 10 Nov 2020

Haggerty K (2004) Ethics creep: governing social science research in the name of ethics. Qual Sociol 27(4):391-414. https:// doi.org/10.1023/B:QUAS.0000049239.15922.a3

Hakim C. (1982) Secondary Analysis and the Relationship between Official and Academic Social Research. Sociology. 16(1):1228. https://doi.org/10.1177/0038038582016001005 
Helle AC, DeShong HL, Lengel GJ, Meyer NA, Butler J, Mullins-Sweatt SN (2018) Utilizing five factor model facets to conceptualize counterproductive, unethical, and organizational citizenship workplace behaviors. Personal Individ Differ 135:113-120. https://doi.org/10.1016/j.paid.2018.06.056

Jawitz J (2009) Learning in the academic workplace: the harmonization of the collective and the individual habitus. Stud High Educ 34(6):601-614. https://doi.org/10.1080/03075070802556149

Johnson EM (2008) An investigation into pedagogical challenges facing international tertiary-level students in New Zealand. High Educ Res Dev 27(3):231-243. https://doi.org/10.1080/07294360802183796

Johnston MP (2012) School librarians as technology integration leaders: enablers and barriers to leadership enactment. School Library Research 15(1) ISSN: 2165-1019. https://www.learntechlib.org/p/55015/

Johnston MP (2014) Secondary data analysis: a method of which the time has come. Qualitative and quantitative methods in libraries, [S.I.], 3(3):619-626, ISSN 2241-1925. http://www.qqml-journal.net/index.php/qqml/article/view/169

Kenny L (2019) Tertary staff 'bullied' to pass students, says new TEU report (authored by Sarah Proctor-Thomson and Charles Sedgwick) The Dominion Post, p. 64. https://www.pressreader.com/similar/281539407379286. Accessed 10 Nov 2020

Lancaster T (2020) Academic discipline integration by contract cheating services and essay Mills. J Academic Ethics 18:115127. https://doi.org/10.1007/s10805-019-09357-x

Levitt HM (2015) Interpretation-driven guidelines for designing and evaluating grounded theory research: a constructivistsocial justice approach. In: Gelo O, Pritz A, Rieken B (eds) Psychotherapy research. Springer, Vienna. http://link.springer. com/chapter/10.1007/978-3-7091-1382-0_22

Lincoln YS, Guba EG (1986) But is it rigorous? Trustworthiness and authenticity in naturalistic evaluation. New Directions for Program Evaluation 1986:73-84. https://doi.org/10.1002/ev.1427

Locke KD, Church AT, Mastor KA, Curtis GJ, SadlerP MDK, Vargas-Flores JJ, Ibáñez-Reyes J, Morio H, Reyes JA, Cabrera HF, Arias RM, Rincon BC, Arias NCA, Muñoz A, Ortiz FA (2017) Cross-situational self-consistency in nine cultures: the importance of separating influences of social norms and distinctive dispositions. Personlaity and Social Psychology Bulletin 43(7):10331049. https://doi.org/10.1177/0146167217704192

Mays TJ, Combrinck M, Aluko FR (2018) Deconstructing dual-mode provision in a digital era. Distance Education 39(2):135139. https://doi.org/10.1080/01587919.2018.1457943

McCrae R, Costa PT (2005) Personality in adulthood: a five-factor theory perspective. ISBN: 9781593852603, 268 pages. Guilford press, New York

Newton P (2016) Academic integrity: a quantitative study of confidence and understanding in students at the start of their higher education. Assess Eval High Educ 41(3):482-497. https://doi.org/10.1080/02602938.2015.1024199

Newton PM (2018) How common is commercial contract cheating in higher education and is it increasing? A systematic review. Frontiers in Education 3:67. https://doi.org/10.3389/feduc.2018.00067

Nørgård RT, Bengtsen SSE (2016) Academic citizenship beyond the campus: a call for the placeful university. High Educ Res Dev 35(1):4-16. https://doi.org/10.1080/07294360.2015.1131669

Pachler N, Cook J, Bachmair B (2010) Appropriation of mobile cultural resources for learning. Int J Mobile and Blended Learning 2(2):1-21. https://doi.org/10.4018/jmbl.2010010101

Podsakoff P.M., MacKenzie S.B., Paine J.B., Bachrach D.G.(2000). Organizational Citizenship Behaviors: A Critical Review of the Theoretical and Empirical Literature and Suggestions for Future Research. Journal of Management. 26(3):513-563. https:// doi.org/10.1177/014920630002600307

Rundle K, Curtis GJ, Clare J (2019) Why students do not engage in contract cheating. Front Psychol 10:2229. ISSN: 1664-1078. https://doi.org/10.3389/fpsyg.2019.02229

Sá CM, Sabzalieva E (2018) The politics of the great brain race: public policy and international student recruitment in Australia, Canada, England and the USA. High Educ 75(2):231-253. https://doi.org/10.1007/s10734-017-0133-1

Sharples M, Taylor J, Vavoula G (2006) A theory of learning for the Mobile age. In: Andrews R, Haythornthwaite C (eds) The sage handbook of Elearning research. Sage, London, pp 221-247

Smith E (2008) Pitfalls and promises: the use of secondary data analysis is educational research. Br J Educ Stud 56(3):323-339. https://doi.org/10.1111/j.1467-8527.2008.00405.x

Spencer L, Ritchie J, Lewis J, Dillon L (2003) Quality in qualitative evaluation: a framework for assessing research evidence. National Centre for social research, ISBN: 0771504465 8, London

Thomson V (2019) Go8 Submission: Tertiary Education Quality and Standards Agency Amendment (Prohibiting Academic Cheating Services) Bill 2019. https://go8.edu.au/go8-submission-tertiary-education-quality-and-standards-agency-a mendment-prohibiting-academic-cheating-services-bill-2019. Accessed 10 Nov 2020

TVNZ Report (2019a, 15 may, 2019) one news [television series episode]. Buying essays from ghostwriters allegedly widespread among international students at NZ universities. Auckland, New Zealand. https:/umw.tvnz.co.nz/one-news/new-zealand/exclusive-buying-essa ys-ghostwriters-allegedly-widespread-among-international-students-nz-universities. Accessed 10 September 2020

TVNZ Report (2019b, 22 may 2019) one news [television series episode]. NZ lecturer says half of international students in their class failed for cheating, universities turning blind eye. Auckland, New Zealand. https:/umw.tvnz.co.nz/one-news/new-zealand/nz-lecturer-says-ha If-international-students-in-their-class-failed-cheating-universities-turning-blind-eye. Accessed 10 September 2020

Twining P, Heller RS, Nussbaum M, Tsai C-C (2017) Some guidance on conducting and reporting qualitative studies, Computers and Education 106:A1-A9. https://doi.org/10.1016/j.compedu.2016.12.002

Unconventional Economist. (2019) Real rankings of Australian universities for international students. Australian Economy. https:// www.macrobusiness.com.au/2019/06/real-rankings-australian-universities-international-students/. Accessed 10 Oct 2020

Wendt M, Åse C (2015) Learning dilemmas in undergraduate student independent essays. Stud High Educ 40(5):838-851. https://doi.org/10.1080/03075079.2013.842967

Widiger TA, Costa PT Jr (2013) Personality disorders and the five-factor model of personality, 3rd edn. American Psychological Association, Washington, DC, US

\section{Publisher's Note}

Springer Nature remains neutral with regard to jurisdictional claims in published maps and institutional affiliations. 